\title{
Evaluation of Antimicrobial Potential and Comparison of HPLC Composition, Secondary Metabolites Count, and Antioxidant Activity of Mentha rotundifolia and Mentha pulegium Extracts
}

\author{
Nada K. Alharbi $\mathbb{D}^{1},{ }^{1}$ Souheila Naghmouchi $\mathbb{D}^{2},{ }^{2}$ and Mayasar Al-Zaban ${ }^{1}{ }^{1}$ \\ ${ }^{1}$ Biology Department, College of Science, Princess Nourah Bint Abdulrahman University, Riyadh 11671, Saudi Arabia \\ ${ }^{2}$ National Research Institute of Rural Engineering, Water, and Forestry, University of Tunis Carthage, \\ Street of Hedi Karay BP. N 10, Ariana 2080, Tunisia
}

Correspondence should be addressed to Souheila Naghmouchi; n.souheila21@yahoo.com

Received 1 July 2021; Accepted 24 August 2021; Published 30 August 2021

Academic Editor: Olufunmiso Olusola Olajuyigbe

Copyright (c) 2021 Nada K. Alharbi et al. This is an open access article distributed under the Creative Commons Attribution License, which permits unrestricted use, distribution, and reproduction in any medium, provided the original work is properly cited.

\begin{abstract}
In the present study, the relationship between the phenolic counts, chemical composition, and biological activities of two Mentha species (Mentha rotundifolia (MR) and Mentha pulegium (MP)) was analyzed. The characterization of the action mode against pathogenic bacteria and the inhibition of spore germination of two fungal species using prepared methanolic extracts were studied here for the first time. The obtained data highlighted the presence of positive correlation between the secondary metabolites contents and the biological activities of the investigated extracts. In fact, HPLC analysis showed that the major components in both the extracts were eriocitrin and rosmarinic acid $(25$ and $20 \mathrm{mg} / \mathrm{ml}$ and 12 and $8 \mathrm{mg} / \mathrm{ml}$ in methanolic extracts of MR and MP, respectively). Moreover, the MR extract was rich in polyphenols and presents the highest antioxidant activity than MP ones. In addition, both extracts possess an antimicrobial activity against four Gram-positive and five Gram-negative bacteria and one yeast species (Candida albicans) and were able to inhibit the spore germination of two fungi species (Aspergillus niger and Aspergillus flavus). But, the significant activity was observed in the presence of MR methanolic extract. The effect of time on cell integrity of E. coli and L. monocytogenes determined by time-kill and bacteriolysis assays showed that the MR extract had a rapid bacteriolytic effect compared to the MP extract, and their capacities were significant against Gram-negative bacteria than positive ones. Based on the obtained data, it can be concluded that Saudi Mentha species have high pharmacological and industrial importance and they can be used in preparation of food or drugs.
\end{abstract}

\section{Introduction}

Several programs have been carried out to discover and develop numerous antimicrobial agents of biological, chemical, synthetic, or natural origin. Indeed, the discovery of antimicrobial drugs in the nineteenth century revolutionized the history of medicine by making it possible to treat many deadly bacterial diseases. Due to the appearance of resistant strains to the usual antibiotics, a change in the clinical spectrum of pathogens, and the emergence of pathogenicity in usually saprophytic strains in our environment, these antibiotics have suffered a decline in their microbial action potential $[1,2]$. This unwanted change in the effectiveness of antibiotics and the loss of their important role as the primary agent in the treatment of infectious diseases has excited researchers to find another alternative that can play the same role with more benefit and less disadvantages [3]. In recent times, the field of modern medicine has increasingly focused interest in synthesizing drugs from plant origin. One of the important traditional sources of raw materials for medicine as well as for production of new preservatives was medicinal plants [4]. Due to their chemical composition and secondary metabolites, the plant extracts play important roles in disease resistance and inhibit the growth of toxic microorganisms in food [5-9].

Food poisoning is caused by a variety of factors, but food poisoning by microorganisms occupies a high percentage. In fact, the major food poisoning-causing bacteria are 
Escherichia coli, Salmonella spp, Staphylococcus aureus, and Bacillus spp [10]. Generally, there are three types of food preservatives: inorganic compounds, organic compounds, and natural food preservatives. Given that the risk and stability of inorganic and organic compounds are increasing [11], it has thus become necessary to develop natural antimicrobial agents.

The genus Mentha, belonging to Lamiaceae family, comprises around 25-30 species that grow in the temperate regions of Eurasia, Australia, and South Africa [12]. The most popular species of Mentha, in Saudi Arabia, is Mentha pulegium which is locally know as Al-Medina mint [13]. In addition to $M$. pulegium, Mentha rotundifolia L. is one of the mint species which have significant importance, both medicinally and commercially. In addition, Mentha spp has been used as a folk remedy for treatment of nausea, bronchitis, flatulence, anorexia, ulcerative colitis, and liver complaints due to its anti-inflammatory, carminative, antiemetic, diaphoretic, antispasmodic, analgesic, stimulant, emmenagogue, and anticatarrhal activities [14, 15]. Indeed, the different parts of Mentha spp are frequently used in herbal teas or as additives in commercial spice mixtures for many foods to offer aroma and flavour.

Several researchers have determined the chemical composition and biological activities of Mentha extract, but according to our knowledge, there are no available studies focused on the characterization of the action mode of Mentha species against bacteria. In addition, the biological activities, in particular, antibacterial, anticandidal, and antifungal capacities, of this plant harvested in Saudi Arabia have been scarcely studied. Therefore, the aims of the current investigation were, firstly, to determine the contents of secondary metabolites in two Mentha species (M. pulegium and $M$. rotundifolia L.) leaves and their antioxidant activity. Then, the antibacterial, anticandidal, and antifungal activities were evaluated using two methods. The characterization of the action mode against E. coli and L. monocytogenes was also assessed by time-kill and lysis assays.

\section{Materials and Methods}

2.1. Plant Material. The leaves of Mentha rotundifolia L. and Mentha pulegium were collected separately from an agronomical region situated in Al-Kharj in Saudi Arabia and identified according to the "Flora of the Kingdom of Saudi" [16]. The samples were dried in the shade away from light at room temperature.

2.2. Methanolic Extract Preparation. After drying in the dark at room temperature, the leaves of $M$. rotundifolia $L$. and M. pulegium were finely ground using blade-carbide grinding (IKA-WERK Type: A: 10). Stirring with $100 \mathrm{ml}$ of pure methanol $(80 \%)$ at room temperature for $24 \mathrm{~h}$ was carried out to extract the samples separately $(10 \mathrm{~g})$. Then, the concentration of the extract to dryness was done using the rotary evaporator. The prepared methanolic extracts were stored in a dark glass at $4^{\circ} \mathrm{C}$ until analyses.
2.3. Phenolic Compound Content. The Folin-Ciocalteu reagent was utilized to estimate the total phenolic concentration in the methanolic extracts obtained from two Mentha species. In fact, the method previously reported by Slinkard and Singleton [17] was used. The results are presented as mg gallic acid equivalents per gram dry weight (mg GAE/g DW) through the calibration curve with gallic acid.

In order to determine the total flavonoid contents in both tested extracts, the aluminum chloride colorimetric method previously described by Djeridane et al. [18] was used. The obtained data are given as rutin equivalents per gram dry weight (mg RE/g DW).

2.4. Chromatographic Conditions. The phenolic composition of two evaluated extracts was estimated using high-performance liquid chromatography (HPLC). In fact, the separation of the phenolic compound was realized using the Beta Basic$18 \mathrm{C} 18$ column $(5 \mu \mathrm{m}, 250 \times 4.6 \mathrm{~mm}$ ID, Thermo Hypersil). The sample was injected at a quantity of $50 \mu \mathrm{l}$, after filtering through a $0.45 \mu \mathrm{m}$ membrane Millipore chromatographic filter. The compounds of $M$. rotundifolia and M. pulegium were analyzed using an acetonitrile/water gradient with formic acid added according to the solvent program, i.e., solvent A with $1.5 \%$ formic acid in acetonitrile and solvent $\mathrm{B}$ with $1.5 \%$ formic acid in water, starting from $15 \%$ A up to $45 \% \mathrm{~A}$ in $\mathrm{B}$ by $25 \mathrm{~min}$. The peaks were monitored at 280 and $330 \mathrm{~nm}$. The flow rate was maintained at $1.0 \mathrm{ml} / \mathrm{min}$. The comparison of the retention time and UV-Vis spectra of the phenolic chromatogram of the fraction with those of pure standards purchased from Sigma ((eriocitrin (45714), hesperidin (50162), narirutin (G003936); luteolin (L9283), rosmarinic acid (536954), and caffeic acid (C0625)) was used for identification of each obtained peaks

\subsection{Antioxidant Activity}

2.5.1. Free Radical Scavenging Activity (DPPH). The antioxidant activity of methanolic extracts of two Mentha species was firstly carried out using the 2, 2-diphenyl-1picrylhydrazyl (DPPH) radical scavenging assay according to the published method by Hatano et al. [19]. The scavenging activity was estimated using the following equation: scavenging effect $(\%)=\left(100 \mathrm{x}\left(A_{0}-A_{1} / A_{0}\right)\right)$, where $A_{0}$ and $A_{1}$ are the absorbance of the control and the sample, respectively. The concentration of extract that could scavenge $50 \%$ of the DPPH radicals $\left(\mathrm{IC}_{50}\right)$ was calculated.

2.5.2. Free Radical Scavenging Ability Using ABTS Radical Cation. The ability of the investigated extracts to scavenge the ABTS radical cation was used to determine the antioxidant activity of both Mentha species. In fact, the method previously described by Re et al. [20] was utilized. The results are presented as the percentage of inhibition of the ABTS cation radical by the samples calculated using the following formula: scavenging effect $(\%)=\left(\left(A_{0}-A_{1}\right) / A_{0}\right) \times 100$, where $A_{0}$ is the absorbance of the blank sample and $A_{1}$ is the absorbance of the sample. 
2.6. Evaluation of Antimicrobial Activity. Four Gram-positive (Staphylococcus aureus ATCC 6538, Bacillus cereus ATCC 1247, Listeria monocytogenes ATCC 7644, and Enterococcus faecalis), five Gram-negative (Escherichia coli ATCC 8739, Pseudomonas aeruginosa ATCC 9027, Salmonella arizona ATCC25922, Salmonella typhimurium NCTC 6017, and Klebsiella pneumoniae) pathogen bacteria, two fungi (Aspergillus niger and Aspergillus flavus), and one yeast (Candida albicans ATCC 2091) species were used to evaluate the antibacterial and antifungal activity of two Mentha species referring to two methods. Three different media were used in the current study: Trypto-Caseine Soy Agar (TSA) for growing the bacterial strains, Potato Dextrose Agar (PDA) for fungal species, and Sabouraud Dextrose Agar (SDA) for Candida albicans.

Preliminary screening for antimicrobial activity of $M$. rotundifolia and $M$. pulegium methanolic extracts was performed by disc diffusion assay [21, 22]. The antibiotics used as positive control for bacteria and fungi were gentamicin $(10 \mu \mathrm{g} / \mathrm{disc})$ and amphotericin B (20 $\mathrm{lg} / \mathrm{disc})$, respectively. Negative control corresponds to the disc without sample. The disc contains the solvent that was employed to determine the solvent activity. The diameter of the growthinhibition zone (including disc diameter of $6 \mathrm{~mm}$ ) was used to estimate the qualitative antimicrobial activity of the tested extract.

The quantitative antimicrobial activity of investigated extracts was evaluated using the determination of minimum inhibitory concentrations (MICs) and minimum bactericidal concentrations (MBC). For that, the broth dilution method as described by Aouadhi et al. [22] was used. Microbial growth was indicated by the presence of turbidity and a "pellet" at the tube bottom. MIC was recorded visually as the lowest concentration in each row that completely inhibited bacterial growth. MBC is usually an extension from the MIC, where the microorganisms are quantitatively indicating the minimum concentration at which no viable organism appears in the culture [22].

2.7. Inhibition of Spore Germination of Fungal Species. The method of Athukorala et al. [23] was adopted to study the effect of both the methanolic extracts on inhibition of spore germination of two fungi species (Aspergillus flavus and Aspergillus niger). The results are expressed as the percentage of the inhibition of spore germination (I\%) determined by microscopic examination using the following formula: $I(\%)=(C-E) / C \times 100$ (where $E$ is the number of spores in the tube containing the suspension of spores + extract and $C$ corresponds to the number of spores counted in the control tube).

2.8. Primary Mode of Action of Methanolic Extracts. The mode of action of two methanolic extracts was assessed by determining the effect of time on cell integrity using time-kill studies and bacteriolysis assay. Two microorganisms representative of Gram-negative and -positive bacteria (E. coli and L. monocytogenes, respectively) was utilized in this assay.
2.8.1. Time-Kill Studies. Time-kill studies allow the characterization of the antibacterial activity of tested extracts by evaluating the reduction of bacterial count in the presence of extracts at their MIC over several hours. In fact, in the current study, the method described by Klepser et al. [24] and modified by Viljoen et al. [25] was used to evaluate the effect of $M$. rotundifolia and $M$. pulegium methanolic extracts against two representing Gram-positive and -negative bacteria. Activities of tested products, used at their MIC, were evaluated against $E$. coli and L. monocytogenes by measuring the reduction in the number of CFU per milliliter over $24 \mathrm{~h}$. A microbial load of $10^{2} \mathrm{CFU}$ was utilized as the limit of quantification by this method [26].

2.8.2. Bacteriolysis. The bacteriolysis assays of tested extracts against $L$. monocytogenes and E. coli were assessed according to the standard method described by Carson et al. [27] and Guinoiseau et al. [26]. The results are presented as a ratio (in percent) of the $\mathrm{OD}_{620}$ at each time point to the $\mathrm{OD}_{620}$ at $0 \mathrm{~min}$.

2.9. Statistical Analysis. The obtained data are expressed as means \pm standard deviation of three replications. Tukey's post hoc tests were used to estimate the significant differences between means, and $P$ values less than 0.05 were regarded as significant using SPSS 14.0 software for Windows (SPSS Inc., Chicago, IL).

\section{Results and Discussion}

3.1. HPLC Analysis. The chemical composition of both the methanolic extracts was determined using HPLC. The comparison with retention time and fragmentation patterns of standard compounds was used as the method for the identification of different compounds. In addition, the quantification was carried out by the external standard method from integrated peak areas of samples at $280 \mathrm{~nm}$ (UV absorption maximum of flavanone glycosides). As shown in Table 1, the presence of seven polyphenolic compounds can be highlighted: eriocitrin, hesperidin, narirutin, luteolin, isorhoifolin, rosmarinic acid, and caffeic acid. Despite both the extracts possessing the same chemical composition, significant variations in the concentration of the identified compounds were registered. In fact, the highest content in total polyphenols was detected in the methanolic extract of $M$. rotundifolia. The composition of Mentha species in polyphenols was earlier examined by Peterson and Simmonds [28], Fatiha et al. [29], and Riahi et al. [15].

The constituents observed for both extracts are well known as bioactive compounds with antioxidant, antimicrobial, anti-inflammatory, and analgesic activities. This evidence justifies the traditional and popular use of their aerial parts.

3.2. Secondary Metabolites Contents and Antioxidant Activity. The biological activity and the secondary metabolites of some species belonging to the Mentha genus were evaluated 
TABle 1: Contents of Mentha rotundifolia and Mentha pulegium polyphenolic compounds determined by HPLC.

\begin{tabular}{lccc}
\hline $\begin{array}{l}\text { Identified } \\
\text { compounds }\end{array}$ & $\begin{array}{c}\text { Content of compounds } \\
\text { (mg/g of dry weight) }\end{array}$ & $\begin{array}{c}\text { Retention } \\
\text { time } \\
\text { M. rotundifolia }\end{array}$ & M. pulegium \\
\hline Eriocitrin & 25 & 20.1 & 12.5 \\
Hesperidin & 0.75 & 0.5 & 17.5 \\
Narirutin & 0.10 & 0.09 & 16.25 \\
Luteolin & 0.22 & 0.2 & 15.5 \\
Isorhoifolin & 2.5 & 1.2 & 14 \\
Rosmarinic acid & 12 & 8 & 18.5 \\
Caffeic acid & 8.55 & 0.3 & 10.5 \\
\hline
\end{tabular}

by some researchers $[9,29,30]$, but there are no published data on Mentha species harvested in Saudi Arabia. In the current investigation, two Mentha species were screened for their secondary metabolites contents and biological activities.

The determination of total phenols and flavonoids contents in methanolic leaf extracts was performed by the spectrophotometric method using the Folin-Ciocalteu and the aluminum chloride reagents, respectively. The obtained data showed the existence of variation in secondary metabolites concentrations according to Mentha species. In fact, significant difference in the amount of total polyphenols was observed between the $M$. rotundifolia (74.45 GAE mg/g DW) and $M$. pulegium (48.4 GAE mg/g DW) extracts. However, the flavonoid contents are almost the same in both extracts $(28.87 \mathrm{RE} \mathrm{mg/g} \mathrm{DW} \mathrm{and} \mathrm{29.3} \mathrm{RE} \mathrm{mg/g} \mathrm{DW} \mathrm{for}$ $M$. pulegium and $M$. rotundifolia, respectively).

Our study confirms the results obtained in previous work which demonstrated that different Mentha species were rich in polyphenols. For example, the content of polyphenol in M. pulegium extract from Tunisia was $43.4 \mathrm{mg}$ GAE/g DW [9]. In the same way, Karray-Bouraoui et al. [31] reported wide ranges varying from 20.1 to $56.6 \mathrm{mg} \mathrm{GAE} / \mathrm{g}$ DW of polyphenols in the methanolic extract of M. pulegium. In addition, Fatiha et al. [29] demonstrated that the M. spicata methanolic extract possesses the highest phenolic content $(12.0 \pm 0.3 \mathrm{mg} \mathrm{GAE} / \mathrm{g})$ than M. pulegium and $M$. rotundifolia extracts and $M$. rotundifolia showed the dominant flavonoid content $(3.3 \pm 0.1 \mathrm{mg} \mathrm{QE} / \mathrm{g})$. Moreover, Nickavar et al. [30] evaluated the contents of secondary metabolites in five Iranian Mentha species and showed that $M$. rotundifolia presents the highest concentration of polyphenols. However, Mata et al. [32] demonstrated that $M$. spicata was rich in total phenolic compounds than M. pulegium.

Concerning antioxidant activity, Table 2 shows that $\mathrm{IC}_{50}$ values varied significantly among Mentha species. Based on the fact that the extract which had lower $\mathrm{IC}_{50}$ value indicated higher antioxidant activity, the M. rotundifolia methanolic extract presents the highest antioxidant activity compared to $M$. pulegium, with $\mathrm{IC}_{50}$ in the presence of ABTS and DPPH being $44 \mu \mathrm{g} / \mathrm{ml}$ and $21 \mu \mathrm{g} / \mathrm{ml}$, respectively (Table 2). In addition, it can be concluded that the high contents of total phenolic compounds contributed to the essential antioxidant activity of $M$. rotundifolia. Moreover, the chemical composition of both tested Mentha species had an important role in their biological activities. Some investigations demonstrated that rosmarinic acid, caffeic acid, and eriocitrin can be used as an antioxidant, scavenging superoxide, and hydroxyl radicals and can inhibit oxidation of lowdensity lipoproteins [33]. We also noticed that both the tested methanolic extracts were rich in the same phenolic compounds.

Some researchers have found that the total phenolic content in Mentha species was proportional to antioxidant activity. In fact, Hajlaoui et al. [14] showed the existence of a linear correlation between antioxidant potential and phenolic content of two Mentha species ( $M$. pulegium and Mentha longifolia). In order to verify this idea, correlation coefficients $(r)$ between antioxidant capacities (DPPH) and phenol contents in two Saudi Mentha leaf extracts were determined and showed that high antioxidant activity corresponded to high total phenolic contents in the tested extracts. In fact, polyphenolic compounds seem to have an important role in stabilizing lipid oxidation and to be associated with antioxidant activity [34].

Based on the literature, it can be noticed that $M$. rotundifolia and $M$. pulegium methanolic extracts exhibited significant antioxidant activity than that described for the same species collected from other countries. For example, the $\mathrm{IC}_{50}$ of $M$. pulegium and $M$. rotundifolia methanolic extracts harvested in Algeria were $42.7 \mu \mathrm{g} / \mathrm{ml}$ and $71.3 \pm 2.6 \mu \mathrm{g} / \mathrm{ml}$, respectively [29].

3.3. Antibacterial Activity. In the present report, the in vitro antibacterial activity of methanolic extracts of two Saudi Mentha species against Gram-positive and Gram-negative bacteria was studied. Table 3 shows the qualitative (determination of inhibition zones) and quantitative (determination of minimum inhibitory concentration (MIC) and minimum bactericidal concentration (MBC)) results of antibacterial activity. Indeed, the two investigated methanolic extracts presented significant antibacterial activity against all tested bacteria, but variations in the degree of this activity according to the Mentha and microorganism species were observed. In fact, the $M$. rotundifolia methanolic extract registered highest inhibition zone diameters with IZ ranging from $12 \mathrm{~mm}$ (B. subtilis) to $17 \mathrm{~mm}$ (E. coli). The lowest value was observed in the presence of $M$. pulegium methanolic extract for $B$. subtilis. The results of bacteriostatic and bactericidal activities of both extracts against tested bacteria are listed in Table 3 and confirmed the disc diffusion results. In fact, the tested extracts possess significant antibacterial activity with the MIC values in the range of $6.25-12.5 \mu \mathrm{g} / \mathrm{ml}$ for M. rotundifolia and $12.5-25 \mu \mathrm{g} / \mathrm{ml}$ for M. pulegium, respectively.

According to the obtained data, it is possible to conclude that the methanolic leaf extract of $M$. rotundifolia can be considered as significant antibacterial agents. These results are not in agreement with those obtained by Ghazghazi et al. [9] and Gulluce et al. [35] who observed that the methanol extract from aerial parts of $M$. pulegium and $M$. longifolia ssp. longifolia plants showed no antimicrobial activities. 
TABLe 2: Antioxidant activities of methanolic extracts of two Mentha species.

\begin{tabular}{lcc}
\hline Species & $\mathrm{DPPH}\left(\mathrm{IC}_{50}, \mu \mathrm{g} / \mathrm{ml}\right)$ & $\mathrm{ABTS}\left(\mathrm{IC} \mathrm{C}_{50}, \mu \mathrm{g} / \mathrm{ml}\right)$ \\
\hline$M$. pulegium & $27.31 \pm 0.94$ & $57.08 \pm 0.85$ \\
$M$. rotundifolia & $21.08 \pm 0.83$ & $44.01 \pm 0.96$ \\
Butylated hydroxytoluene (BHT) & 20 & 46 \\
\hline
\end{tabular}

Values are given as mean $\pm \operatorname{SD}(n=3)$.

TABle 3: Antibacterial and antifungal activities of Mentha methanolic extracts against nine bacteria evaluated by disc diffusion and determination of MIC and MBC tests.

\begin{tabular}{|c|c|c|c|c|c|c|c|}
\hline \multirow{2}{*}{ Strains ${ }^{\mathrm{a}}$} & \multicolumn{3}{|c|}{ Inhibition zone diameters $(\mathrm{mm})^{\mathrm{b}}$} & \multicolumn{2}{|c|}{ MIC $(\mu \mathrm{g} / \mathrm{ml})$} & \multicolumn{2}{|c|}{$\mathrm{MBC}(\mu \mathrm{g} / \mathrm{ml})$} \\
\hline & MR & MP & Antibiotics & MR & MP & MR & MP \\
\hline \multicolumn{8}{|l|}{ Gram-negative bacteria } \\
\hline E. coli ATCC 8739 & $17 \pm 0.5$ & $16 \pm 0.5$ & 24 & 12.5 & 25 & 12.5 & 25 \\
\hline S. typhimurium NCTC 6017 & $15 \pm 1$ & $14 \pm 0.5$ & 23 & 12.5 & 25 & 25 & 50 \\
\hline S. arizona ATCC 25922 & $15 \pm 0.7$ & $14 \pm 0.4$ & 23 & 12.5 & 25 & 25 & 50 \\
\hline P. aeruginosa ATCC 27853 & $17 \pm 0.8$ & $16 \pm 0.3$ & 21 & 12.5 & 25 & 12.5 & 25 \\
\hline Klebsiella pneumoniae & $15 \pm 0.5$ & $14 \pm 0.4$ & 20 & 6.25 & 12.5 & 12.5 & 25 \\
\hline \multicolumn{8}{|l|}{ Gram-positive bacteria } \\
\hline L. monocytogenes ATCC 7644 & $13 \pm 0.5$ & $12 \pm 0.5$ & 18 & 12.5 & 25 & 25 & 50 \\
\hline B. cereus ATCC 1247 & $12 \pm 0.5$ & $11 \pm 0.6$ & 21 & 12.5 & 25 & 25 & 50 \\
\hline E. faecalis & $14 \pm 0.6$ & $13 \pm 0.3$ & 19 & 12.5 & 25 & 12.5 & 25 \\
\hline S. aureus & $15 \pm 0.4$ & $14 \pm 0.2$ & 20 & 12.5 & 25 & 25 & 50 \\
\hline \multicolumn{8}{|l|}{ Fungus species } \\
\hline Aspergillus flavus & $14 \pm 0.4$ & $13 \pm 0.4$ & 11 & 12.5 & 12.5 & 25 & 25 \\
\hline Aspergillus niger & $16 \pm 0.5$ & $15 \pm 0.3$ & 11 & 12.5 & 12.5 & 25 & 25 \\
\hline Candida albicans & $11 \pm 0.6$ & $11 \pm 0.4$ & 17 & 12.5 & 12.5 & 25 & 25 \\
\hline
\end{tabular}

${ }^{a}$ The final bacterial density was around $10^{5} \mathrm{cfu} / \mathrm{mL}$. ${ }^{\mathrm{b}}$ Inhibition zone diameters $(\mathrm{mm})$ produced around the wells were determined by adding $15 \mu \mathrm{L}$ of methanol extracts. MIC: minimum inhibitory concentration $(\mu \mathrm{g} / \mathrm{ml})$; MBC: minimum bactericidal concentration $(\mu \mathrm{g} / \mathrm{ml})$. Values are means of three measurements; \pm : standard deviation.

Recently, Riahi et al. [15] indicated that the M. rotundifolia methanolic extract exhibited antibacterial potential against five bacterial strains.

As for the secondary metabolites contents, same differences were found between the antimicrobial activities of methanolic extracts of two Mentha species. Our results suggest that the notable antibacterial property can be attributed to their phenolic compounds. Indeed, $M$. rotundifolia leaf extracts exhibited a high amount of bioactive phenolic compounds and notable antimicrobial activity than the $M$. pulegium extract. In the same way, previous findings highlighted the presence of positive correlation between total phenolic contents and antimicrobial activity $[14,36]$.

3.4. Characterization of the Action Mode of Methanolic Extracts. Generally, the target organ of active compounds in the plant extract is the cell membrane of bacteria. In fact, Hamouda and Baker [37] showed that active constituents might attack the cell wall and cell membrane, thereby destroying their permeability barrier and causing the release of intracellular constituents like ribose and sodium glutamate. Also, they interfere with electron transport, nutrient uptake, protein and nucleic acid synthesis, and enzyme activity, leading to the inhibition of bacterial growth. In the current finding, the characterization of the mechanisms of action of two Mentha species methanolic extracts was carried out for the first time. In fact, experiments on cell death and bacteriolysis of evaluated extracts against two bacterial species (E. coli and L. monocytogenes) were used to measure the effects induced by time-dependent treatments on cell viability.

3.4.1. Dynamics Action of the Methanolic Extract: Time-Kill Analysis. In order to study the antibacterial action mode of evaluated extracts, the growth of two selected bacteria (L. monocytogenes and E. coli) were monitored, in the absence and presence of extracts at a concentration corresponding to the MIC over a period of 24 hours. As presented in Figure 1, the control population shows a classic growth curve with three phases (growth, stationary, and decline phases). In the presence of each extract at a concentration corresponding to MIC, the shape of the growth curve is reversed and the three phases no longer appear indicating the cessation of growth of both bacterial strains after incubation for 24 hours at $37^{\circ} \mathrm{C}$. In fact, after 2 hours of treatment, the number of viable cells decreased. It reaches the limit of detection (inhibition of about $50 \%$ of the initial population $=2 \log (\mathrm{CFU} / \mathrm{ml}))$ after $8 \mathrm{~h}$ and $4 \mathrm{~h}$ for E. coli and L. monocytogenes, respectively, in the presence of $M$. rotundifolia and after $8 \mathrm{~h}$ for both bacterial species in the presence of $M$. pulegium methanolic extract. Based on these results, it can be signaled that the bactericidal effect of Mentha methanolic extracts depends on the duration of 


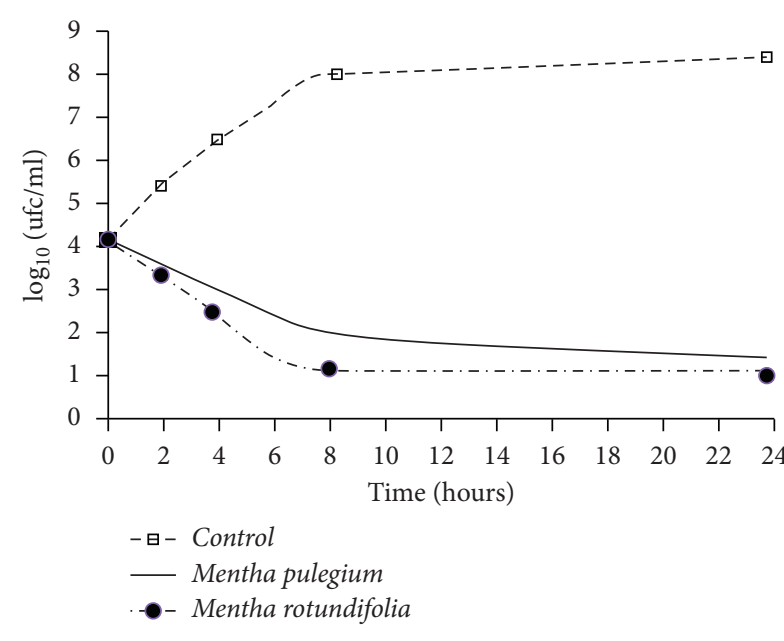

(a)

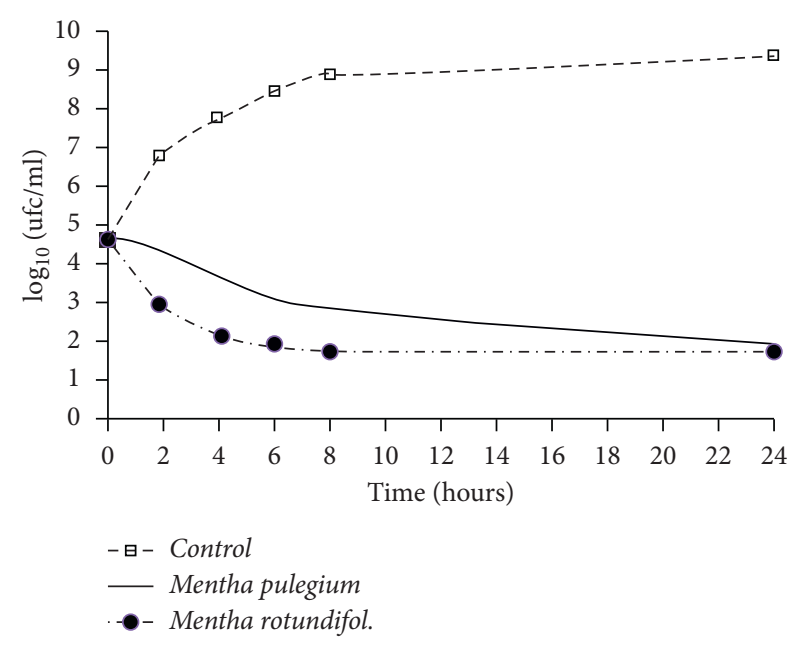

(b)

Figure 1: Time-kill curves E. coli (a) and L. monocytogenes (b) cultures untreated and treated with the methanolic extract of two Mentha species at a concentration corresponding to the MIC.

incubation, bacterial species, and evaluated Mentha species. In fact, $M$. rotundifolia had the highest bactericidal activity than M. pulegium and shows more efficiency against E. coli (Gram-negative bacteria) than L. monocytogenes (Grampositive bacteria).

3.4.2. Determination of the Lytic Action of the Methanolic Extract. The measure of the absorbance of the bacterial strains in the absence and presence of each extract, at a concentration corresponding to MIC, was used to determine the lytic action of the methanolic extract of two Saudi Mentha species against two bacterial species (L. monocytogenes and E. coli). The loss of absorbance after 2 hours of incubation is evaluated based on the initial absorbance. The results are therefore expressed as the ratio of the absorbance measured at time $T$ to the absorbance at $620 \mathrm{~nm}$ measured at time zero $\left(\left(\mathrm{OD}_{620}(T) / \mathrm{OD}_{620}\left(T_{0}\right)\right) \times 100\right)$.

Figure 2 shows that in the case of control (without extract), the absorbance of two bacterial strains are around $100 \%$ indicating the absence of cell lysis. However, the addition of extract caused a decrease in the initial absorbance of both bacteria. Indeed, the optical density decreased to $50 \%$ and $70 \%$ for E. coli and L. monocytogenes, respectively, in the presence of both Mentha species.

Usually, some antimicrobial agents destroy the bacterial membrane irreversibly leading to cell death by a lytic process [37-39]. Indeed, the obtained data confirmed the time-kill assay in that the methanolic extract of two Mentha species had a bacteriolytic effect against two different categories of bacteria, Gram-positive and Gram-negative, which are not of the same potency. Indeed, E. coli was more sensitive to the effect of the tested extract than L. monocytogenes. These results are in conformity with those of Horne et al. [40]. In fact, these authors demonstrated that the essential oils of oregano, rosewood, and thyme generate lytic effects against Streptococcus pneumoniae. However, in other works, we observed that plant extracts compromise the structural

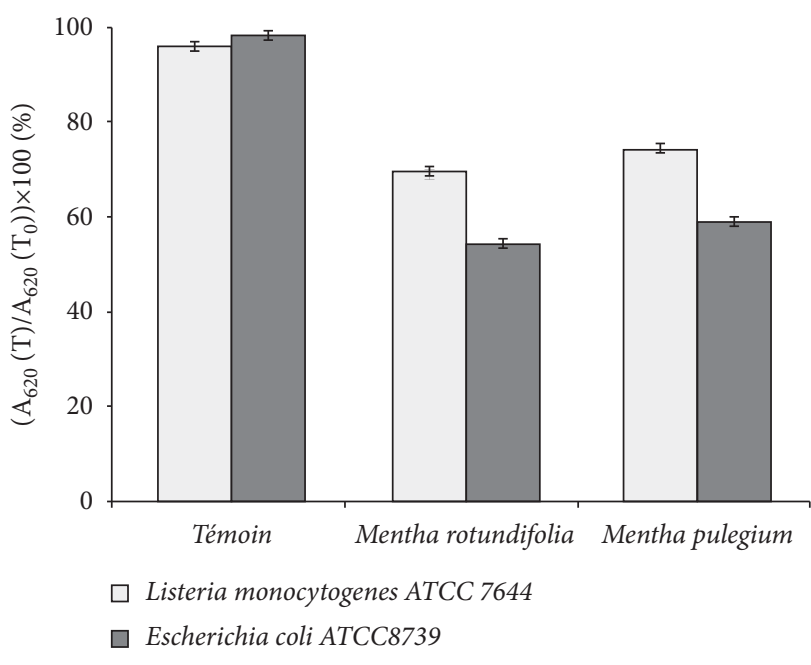

FIGURE 2: Cell integrity of E. coli and L. monocytogenes after treatment with two Mentha extracts at a concentration corresponding to the MIC.

integrity of the plasma membrane and induce loss of the cytoplasm material but do not lyse bacterial cells [27, 41].

Previous works signaled that the antimicrobial effect of plant extracts was greater on Gram-positive bacteria than on negative ones. This is due to the difference in their cell wall (membrane proteins of Gram-negative organisms acting as a barrier to many environmental substances, including antimicrobial agents) [42]. In our finding, Saudi Mentha species had in vitro selective antibacterial activity on the basis of the cell-wall differences of bacterial microorganisms with the Gram-negative bacteria being more sensitive than Grampositive bacteria.

3.5. Antifungal Activity and Inhibition of Spore Germination. The chemical composition and antibacterial activity of $M$. rotundifolia and $M$. pulegium methanolic extracts have 
been investigated by some researchers, but their antifungal and anticandidal activities have been scarcely studied. In the current study, the antifungal and anticandidal activities of two Saudi Mentha methanolic extracts as well as the inhibition of spore germination of $A$. flavus and A. niger were investigated. Generally, the main pathogenic fungal species for humans, animals, and plants are Aspergillus niger and Aspergillus flavus. In fact, they able to cause aspergillosis in immunocompromised individuals as well as postharvest disease in cereal grains and legumes [43, 44]. The antifungal activity results showed that the methanolic extracts exhibited a moderate activity against yeast (C. albicans) and two fungi species (A. flavus and A. niger) with the maximum inhibition zones and MIC values ranging from 10 to $13 \mathrm{~mm}$ and 12.5 to $25 \mu \mathrm{g} / \mathrm{ml}$, respectively (Table 3 ).

Concerning the inhibition of spore germination, the M. rotundifolia methanol extract exhibited the highest activity against the two fungal species with the inhibition rate around $35 \%$, whereas with the M. pulegium extract, it was 50\%. These data clearly showed that the Saudi Mentha species were able to inhibit the spore germination of Aspergillus spp.

\section{Conclusion}

The obtained data highlight the importance of Saudi Mentha species as a promising source of natural antioxidant, antifungal, and antibacterial agents for food preservation and the prevention against oxidative stress-related disease and pathogenic bacteria.

\section{Data Availability}

No data were used to support this study.

\section{Conflicts of Interest}

The authors declare that they have no conflicts of interest in this paper.

\section{Authors' Contributions}

Souheila Naghmouchi was involved in conceptualization, methodology, formal analysis, investigation, data curation, and writing of the manuscript. Mayasar Al -Zaban contributed to methodology, validation, resource provision, supervision, reviewing, and editing. Nada K. Alharbi carried out methodology, validation, resources, supervision, reviewing, and editing. Nada K. Alharbi and Souheila Naghmouchi contributed equally.

\section{Acknowledgments}

This research was funded by the Deanship of Scientific Research at Princess Nourah Bint Abdulrahman University through the Fast-Track Research Funding Program.

\section{References}

[1] D. J. Newman, G. M. Cragg, and K. M. Snader, "The influence of natural products upon drug discovery (antiquity to late
1999)," Natural Product Reports, vol. 17, no. 3, pp. 215-234, 2000.

[2] K. Poole, "Efflux-mediated antimicrobial resistance," Journal of Antimicrobial Chemotherapy, vol. 56, no. 1, pp. 20-51, 2005.

[3] A. S. Al-Zubairi, A. B. Abdul, M. M. Elhassan, M. Youssif, S. I. A. Wahab, and S. Moham, "Antibacterial and antioxidant activities of Typhonium flagelliforme (Lodd.) blume tuber," American Journal of Biochemistry and Biotechnology, vol. 4, pp. 402-407, 2008.

[4] M. Al-Fatimi, M. Wurster, G. Schröder, and U. Lindequist, "Antioxidant, antimicrobial and cytotoxic activities of selected medicinal plants from Yemen," Journal of Ethnopharmacology, vol. 111, no. 3, pp. 657-666, 2007.

[5] M. Antolovich, P. Prenzler, K. Robards, and D. Ryan, "Sample preparation in the determination of phenolic compounds in fruits," The Analyst, vol. 125, no. 5, pp. 989-1009, 2000.

[6] M. Servili and G. Montedoro, "Contribution of phenolic compounds to virgin olive oil quality," European Journal of Lipid Science and Technology, vol. 104, no. 9-10, pp. 602-613, 2002.

[7] J. H. Bae, "Antimicrobial effect of Pulsatilla koreana extracts on food-borna pathogen," Korean Journal of Nutrition, vol. 37, pp. 655-661, 2004.

[8] K. S. Chung, J. Y. Kim, and Y. M. Kim, "Comparison of antibacterial activities of garlic juice and heat-treated garlic juice," Korean Journal of Food Science and Technology, vol. 35, pp. 540-543, 2003.

[9] H. Ghazghazi, A. Chedia, M. Weslati et al., "Chemical composition and in vitro antimicrobial activities of Mentha pulegium leaves extracts against foodborne pathogens," Journal of Food Safety, vol. 33, no. 3, pp. 239-246, 2013.

[10] Y.-H. Jeon, X. Sun, and M.-R. Kim, "Antimicrobial activity of the ethanol extract from rubus coreanum against microorganisms related with foodborne illness," Korean Journal of Food and Cookery Science, vol. 28, no. 1, pp. 9-15, 2012.

[11] J. H. Lee and I. H. Kim, "Antimicrobial activity and stability of tetrasodium pyrophosphate peroxidate," Korean Journal of Food Science and Technology, vol. 30, pp. 1040-1044, 1998.

[12] H. J. D. Dorman, M. Koşar, K. Kahlos, Y. Holm, and R. Hiltunen, "Antioxidant properties and composition of aqueous extracts from mentha species, hybrids, varieties, and cultivars," Journal of Agricultural and Food Chemistry, vol. 51, no. 16 , pp. $4563-4569,2003$.

[13] L. Moreno, R. Bello, E. Primo-Yúfera, and J. Esplugues, "Pharmacological properties of the methanol extract from mentha suaveolens Ehrh," Phytotherapy Research, vol. 16, no. S1, pp. 10-13, 2002.

[14] H. Hajlaoui, N. Trabelsi, E. Noumi et al., "Biological activities of the essential oils and methanol extract of tow cultivated mint species (Mentha longifolia and Mentha pulegium) used in the Tunisian folkloric medicine," World Journal of Microbiology and Biotechnology, vol. 25, no. 12, pp. 2227-2238, 2009.

[15] L. Riahi, H. Chakroun, I. Klay, A. S. Masmoudi, A. Cherif, and N. Zoghlami, "Metabolomic fingerprint of mentha rotundifolia L. leaf tissues promotes this species as a potential candidate for sustainable production of biologically active molecules," Journal of Complementary and Integrative Medicine, vol. 16, no. 2, Article ID 20180048, 2018.

[16] S. A. Chaudhary, Flora of The Kingdom of Saudi, Vol. 2, Ministry of Agriculture and Water, Riyadh, Saudi Arabia, 2000. 
[17] K. Slinkard and V. Singleton, "Total phenol analysis: automation and comparison with manual methods," American Journal of Enology and Viticulture, vol. 28, pp. 49-55, 1977.

[18] A. Djeridane, M. Yousfi, B. Nadjemi, D. Boutassounaa, P. Stocker, and N. Vidal, "Antioxidant activity of some algerian medicinal plants extracts containing phenolic compounds," Food Chemistry, vol. 97, no. 4, pp. 654-660, 2006.

[19] T. Hatano, H. Kagawa, T. Yasuhara, and T. Okuda, "Two new flavonoids and other constituents in licorice root: their relative astringency and radical scavenging effects," Chemical and Pharmaceutical Bulletin, vol. 36, no. 6, pp. 2090-2097, 1988.

[20] R. Re, N. Pellegrini, A. Proteggente, A. Pannala, M. Yang, and C. Rice-Evans, "Antioxidant activity applying an improved ABTS radical cation decolorization assay," Free Radical Biology and Medicine, vol. 26, no. 9-10, pp. 1231-1237, 1999.

[21] NCCLS (National Committee for Clinical Laboratory Standards), "Performance standards for antimicrobial disk susceptibility test," Approved Standard, M2-A6, Wayne, PA, USA, Sixth edition, 1997.

[22] C. Aouadhi, H. Ghazghazi, B. Hasnaoui, and A. Maaroufi, "Total phenolic content, antioxidant and antibacterial activities of Marrubium vulgare methanolic extract," International Journal of Medicinal Plants and Natural Products, vol. 11, pp. 1737-8907, 2014.

[23] S. N. P. Athukorala, W. G. D. Fernando, K. Y. Rashid, T. de Kievit, and T. D. Kievit, "The role of volatile and nonvolatile antibiotics produced by pseudomonas chlororaphisstrain PA23 in its root colonization and control of sclerotinia sclerotiorum," Biocontrol Science and Technology, vol. 20, no. 8, pp. 875-890, 2010.

[24] M. E. Klepser, E. J. Ernst, R. E. Lewis, M. E. Ernst, and M. A. Pfaller, "Influence of test conditions on antifungal timekill curve results: proposal for standardized methods," Antimicrobial Agents and Chemotherapy, vol. 42, no. 5, pp. 1207-1212, 1998.

[25] A. Viljoen, S. Van Vuuren, E. Ernst et al., "Osmitopsis asteriscoides (asteraceae)-the antimicrobial activity and essential oil composition of a cape-dutch remedy," Journal of Ethnopharmacology, vol. 88, no. 2-3, pp. 137-143, 2003.

[26] E. Guinoiseau, A. Luciani, D. d. R. Serra, Y. Quilichini, L. Berti, and V. Lorenzi, "Primary mode of action of cistus ladaniferus L. essential oil active fractions on Staphylococcus aureus strain," Advances in Microbiology, vol. 5, no. 13, pp. 881-890, 2015.

[27] C. F. Carson, B. J. Mee, and T. V. Riley, "Mechanism of action of melaleuca alternifolia (tea tree) oil on Staphylococcus aureus determined by time-kill, lysis, leakage, and salt tolerance assays and electron microscopy," Antimicrobial Agents and Chemotherapy, vol. 46, no. 6, pp. 1914-1920, 2002.

[28] M. Peterson and M. S. J. Simmonds, "Rosmarinic acid," Phytochemistry, vol. 62, pp. 121-125, 2003.

[29] B. Fatiha, H. Didier, G. Naima et al., "Phenolic composition, in vitro antioxidant effects and tyrosinase inhibitory activity of three algerian mentha species: M. spicata (L.), M. pulegium (L.) and M. rotundifolia (L.) huds (lamiaceae) M. pulegium (L.) and M. rotundifolia (L.) huds (lamiaceae)," Industrial Crops and Products, vol. 74, pp. 722-730, 2015.

[30] B. Nickavar, A. Alinaghi, and M. Kamalinejad, "Evaluation of the antioxidant properties of five Mentha species," Iranian Journal of Pharmaceutical Research, vol. 7, pp. 203-209, 2008.

[31] N. Karray-Bouraoui, R. Ksouri, H. Falleh et al., "Effects of environment and development stage on phenolic content and antioxidant activities of mentha Pulegium L," Journal of Food Biochemistry, vol. 34, pp. 79-89, 2010.

[32] A. T. Mata, C. Proença, A. R. Ferreira, M. L. M. Serralheiro, J. M. F. Nogueira, and M. E. M. Araújo, "Antioxidant and antiacetylcholinesterase activities of five plants used as Portuguese food spices," Food Chemistry, vol. 103, no. 3, pp. 778-786, 2007.

[33] B. Fuhrman, M. Rosenblat, T. Hayek, R. Coleman, and M. Aviram, "Ginger extract consumption reduces plasma cholesterol, inhibits LDL oxidation and attenuates development of atherosclerosis in atherosclerotic, apolipoprotein E-deficient mice," The Journal of Nutrition, vol. 130, no. 5, pp. 1124-1131, 2000.

[34] İ. Gülçin, M. E. Büyükokuroğlu, M. Oktay, and Ö. İ. Küfrevioğlu, "Antioxidant and analgesic activities of turpentine of Pinus nigra Arn. subsp. pallsiana (Lamb.) holmboe," Journal of Ethnopharmacology, vol. 86, no. 1, pp. 51-58, 2003.

[35] M. Gulluce, F. Sahin, M. Sokmen et al., "Antimicrobial and antioxidant properties of the essential oils and methanol extract from Mentha longifolia L. ssp. longifolia," Food Chemistry, vol. 103, no. 4, pp. 1449-1456, 2007.

[36] Y. Zhang, W. G. D. Fernando, T. R. d. Kievit, C. Berry, F. Daayf, and T. C. Paulitz, "Detection of antibiotic-related genes from bacterial biocontrol agents with polymerase chain reaction," Canadian Journal of Microbiology, vol. 52, no. 5, pp. 476-481, 2006.

[37] T. Hamouda and J. R. Baker, "Antimicrobial mechanism of action of surfactant lipid preparations in enteric gram-negative bacilli," Journal of Applied Microbiology, vol. 89, no. 3, pp. 397-403, 2000.

[38] M.-J. Song and M.-N. Kim, “Antimicrobial action of $p$ hydroxyphenyl acrylate," International Biodeterioration \& Biodegradation, vol. 52, no. 2, pp. 107-113, 2003.

[39] M. Razzaghi-Abyaneh, M. Shams-Ghahfarokhi, M. Kawachi et al., "Ultrastructural evidences of growth inhibitory effects of a novel biocide, akacidplus, on an aflatoxigenic aspergillus parasiticus," Toxicon, vol. 48, no. 8, pp. 1075-1082, 2006.

[40] D. Horne, M. Holm, C. Oberg, S. Chao, and D. G. Young, "Antimicrobial effects of essential oils on streptococcus pneumoniae," Journal of Essential Oil Research, vol. 13, no. 5, pp. 387-392, 2001.

[41] J. Reichling, A. Weseler, U. Landvatter, and R. Saller, "Bioactive essential oils used in phytomedicine as anti-infective agents: Australian tea tree oil and manuka oil," Act Pythoter, vol. 1, pp. 26-32, 2002.

[42] N. Vukovic, T. Milosevic, S. Sukdolak, and S. Solujic, "Antimicrobial activities of essential oil and methanol extract of teucrium montanum," Evidence-Based Complementary and Alternative Medicine, vol. 4, Article ID 368170, 4 pages, 2007.

[43] G. N. Agrios, Plant Pathology, Elsevier Academic Press, Cambridge, MA, USA, Fifth edition, 2005.

[44] S. Amaike and N. P. Keller, "Aspergillus flavus," Annual Review of Phytopathology, vol. 49, no. 1, pp. 107-133, 2011. 